\title{
How do practice nurses see their role in childhood injury prevention?
}

\author{
Denise Kendrick, Patricia Marsh, EI Williams
}

\begin{abstract}
Objectives-To assess the knowledge of unintentional injury epidemiology, the attitudes towards, and current practices in injury prevention among practice nurses.
\end{abstract} general practitioners in Nottinghamshire, United Kingdom.

Method-A postal questionnaire was sent to all practice nurses on the Family Health Services Authority list $(n=322)$ with questions covering sociodemographic details, occupational details, unintentional injury epidemiology, attitudes towards the injury prevention activities suggested by a government report as part of the role of the primary health care team, and current practices in injury prevention.

Results- A response rate of $71 \cdot 1 \%$ was achieved. More than $50 \%$ knew that unintentional injuries were the most common cause of death in childhood. A similar per cent knew the site of most fatal injuries in the under 1 and 5-16 year age groups. More than two thirds correctly identified a range of risk factors for unintentional injury. However, only two fifths of nurses believed they could be effective in preventing injuries. There were considerable gaps between attitudes and practice for most activities. The activities most commonly undertaken include displaying posters and leaflets $(69.4 \%)$, giving advice on prevention $(51.1 \%)$, and advice on first aid (45.0\%) during injury consultations.

Conclusions-Most practice nurses hold positive attitudes towards injury prevention activities, but fewer undertake these activities regularly. The activities most commonly undertaken employ an educational model. Further research is needed on the barriers to practice nurses undertaking more injury prevention work, the effectiveness of systems to overcome such barriers, and the effectiveness of these injury prevention activities.

(Injury Prevention 1995; 1: 159-163)

Keywords: practice nurses, primary health care.

Correspondence to: Dr D Kendrick, Departmen DrD Kendrick, Department
of Public Health Medicine of Public Health Medic and Epidemiology, University of Nottingham Medical School, Clifton
Boulevard, Nottingham NG7 2UH, UK In 1984 the Royal College of Nursing defined the role of the practice nurse as 'a registered
Setting-Practice nurses employed by

general nurse who is employed by a general practitioner to work within the treatment room and is a member of a team responsible for the clinical nursing care of the practice population together with the district nursing team of the health authority'. ${ }^{1}$ The role of the practice nurse has expanded over the last 10 years, and it now involves a wide range of activities including providing treatments, immunisations, screening, investigative procedures, and health promotion. ${ }^{2-10}$ The inclusion of health promotion as a contractual requirement in the 1990 general practitioner contract facilitated the development of nurse led health promotion activities in primary care,${ }^{45}$ and has been partly responsible for a rapid expansion in the number of practice nurses employed by general practitioners. ${ }^{10}$

The role of these nurses in childhood injury prevention in the United Kingdom has, so far, received little attention. The government's health strategy, the Health of the Nation suggests that the primary health care team should be involved in injury prevention by undertaking a range of activities. These include the collection of data, the provision of safety advice to individuals and communities, participation in safety equipment loan schemes, checking homes for hazards, advice regarding disposal of unwanted medicines, giving advice on first aid, and membership of local healthy alliances. ${ }^{11}$ However, no mention is made of the specific part practice nurses are expected to play. Few of the published studies addressing the role of the practice nurse $e^{2-10}$ have discussed injury prevention. Those that have confined themselves to first aid for injuries ${ }^{4589}$ or assisting at resuscitation. ${ }^{7}$ The majority of these studies have highlighted the training needs of practice nurses, but again, none have discussed these needs in terms of injury prevention..$^{2-46810}$

Practice nurses have previously been found to hold a diverse range of views concerning health promotion. The majority favour an educational model (promoting an understanding of health issues to enable the patient to make an informed choice) or a behavioural change model (encouraging people to change to healthier lifestyles), in preference to a social change model (working to change political and social environments to make healthier choices easier choices). ${ }^{6}$ In practice, however, most nurses adhere to a narrow medical model (promoting medical intervention through persuasive methods, screening, vaccination, etc). This may not, however, be the most effective model for injury prevention, where issues of social inequality and poverty often need to be 
The opportunities that practice nursing provides for injury prevention are great. ${ }^{14}$ Many nurses deal with minor injuries in the surgery $^{457}$ ) and could offer advice on first aid or prevention at these consultations, as well as collecting and analysing data on the injuries that present to them. Similarly, many nurses do immunisations $s^{4-610}$ and could offer injury prevention advice appropriate to the developmental stage of the child, while nurses who make home visits ${ }^{410}$ could identify hazards in the home. All are members of their communities and could be involved in lobbying or campaigning on local safety issues. ${ }^{14}$ This study therefore aims to assess the knowledge of practice nurses of childhood unintentional injury epidemiology, their attitudes towards, and their current practices, in injury prevention.

\section{Methods}

A questionnaire concerning injury prevention was designed and piloted on a group of 10 practice nurses. The questionnaire and stamped addressed envelope was mailed to all practice nurses in Nottinghamshire $(n=322)$, using the Family Health Services Authority list as the sampling frame. Two further questionnaires were sent to non-responders.

The questionnaire included four sections. The first consisted of attitudinal statements concerning injury prevention activities, including those suggested in the Health of the Nation for the primary health care team. ${ }^{11}$ Possible responses ranged from strongly agree to strongly disagree on a five point Likert scale. The reliability of the attitudinal section of the questionnaire has been assessed by calculating correlation coefficients between each attitudinal statement and the total score (excluding the score for that attitudinal statement) and by calculating Cronbach's alpha coefficient. ${ }^{15}$ The second section consisted of questions concerning current practice with responses ranging from always to never, with a not applicable category, again covering the activities suggested in the Health of the Nation. ${ }^{11}$ Content validity for the attitudinal and current practice sections was established by obtaining the views of practice nurses belonging to a local practice nurse educational group and by ensuring that all pertinent activities were covered. The knowledge questions consisted of questions covering the subject matter included in the Child Accident Prevention Trust's (CAPT) 'picture of childhood accidents' questionnaire. ${ }^{16}$ Additional questions concerning risk factors and the type of accident most commonly requiring accident and emergency department attendance were added. This questionnaire was originally developed by the CAPT as an educational tool to be used when training for health visitors. It was adapted for postal use, and again content validity was established from the views of practice nurses, as above. The validity of the questionnaire in measuring knowledge was assessed by using it with 58 members of primary health care teams before, and between two and four months after, accident prevention training during which information covering each of the knowledge questions was provided. The correct answers to the knowledge questions were obtained from the information sheet provided by the CAPT. ${ }^{16}$ In addition, information was also obtained from the Office of Population Censuses and Surveys mortality statistics $^{17}$ and from the Home Accident Surveillance System. ${ }^{18} 19$ The final section concerned personal and sociodemographic characteristics of age, sex, qualifications, experience in health visiting, paediatric or school nursing, whether the respondent had any children, and their children's injury histories.

The data were entered and analysed using the SPSS-PC statistical package. The knowledge score was computed by totalling all correct responses. The attitude score was computed by totalling all strongly agree or agree responses to positive statements, and all strongly disagree or disagree responses to negative statements. Comparisons of categorical data were made using $\chi^{2}$ tests; comparisons of knowledge and attitude scores by personal and sociodemographic characteristics were made using Mann-Whitney $U$ tests; and correlations between knowledge and attitude scores used the Spearman rank correlation coefficient.

\section{Results}

Altogether 229 usable questionnaires were returned - a response rate of $71 \cdot 1 \%$. The age and number of years as a practice nurse are shown in table 1 . Only $4 \%$ (nine) were qualified children's nurses, $8 \%$ (19) had worked as a school nurse for six months or more, and $2 \%$ (four) were qualified as health visitors. Eighty seven per cent (198) had children. The children of $57 \%$ (113) of the practice nurses who were parents had attended an accident and emergency department after an injury and 14\% (28) had been admitted to hospital after an injury.

\section{KNOWLEDGE OF UNINTENTIONAL INJURY} EPIDEMIOLOGY

A significant increase in knowledge score was demonstrated in the group of primary health care team members undergoing training. The mean score increased significantly for each professional group following training. (Wilcoxon matched pairs test, general practitioners, $\mathrm{p}=0.003$; health visitors, $\mathrm{p}=0.002$; and practice nurses, $p=0.006$ ). This suggests the knowledge section of the questionnaire was a

Table 1 Age and length of employment as a practice nurse

\begin{tabular}{lllc}
\hline Age (years) & No $(\%)$ & $\begin{array}{l}\text { Years in prac- } \\
\text { tice nursing }\end{array}$ & No $(\%)$ \\
\hline$<35$ & $66(28 \cdot 8)$ & $<5$ & $159(69 \cdot 4)$ \\
$35-44$ & $89(38.9)$ & $5-10$ & $54(23 \cdot 6)$ \\
$45-54$ & $65(28.4)$ & $11-15$ & $7(3.1)$ \\
$55-64$ & $9(3.9)$ & $16-20$ & $8(3.5)$ \\
$\geqslant 65$ & 0 & $>20$ & $1(0 \cdot 4)$ \\
Total & $229(100)$ & Total & $229(100)$ \\
\hline
\end{tabular}


valid instrument for measuring knowledge of unintentional injury epidemiology.

Table 2 demonstrates the epidemiological knowledge of practice nurses. More than half were aware that injuries are the most common cause of death over the age of 1 year $(65.5 \%$ of responding nurses correctly identified injuries as the most common cause of death for the 1-4 year age group and $60 \cdot 3 \%$ for the $5-16$ years age group, respectively). Similarly, more than half were aware that most fatal injuries take place in the home for those under 1 year $(79.9 \%$ responded correctly), whereas transport

Table 2 Practice nurses' knowledge of childhood unintentional injury epidemiology with correct answers in parentheses (ages in years)

\begin{tabular}{|c|c|}
\hline Question & $\begin{array}{l}\text { No }(\%) \\
\text { answering } \\
\text { correctly }\end{array}$ \\
\hline $\begin{array}{l}\text { What is the most common cause of death in children? } \\
<1 \text { (SIDS) } \\
1-4 \text { (accidents) } \\
5-16 \text { (accidents) }\end{array}$ & $\begin{array}{r}67(29 \cdot 3) \\
150(65 \cdot 5) \\
138(60 \cdot 3)\end{array}$ \\
\hline $\begin{array}{l}\text { What is the trend in child accident death rates in the UK over the last } 20 \\
\text { years? (falling) }\end{array}$ & $16(7 \cdot 0)$ \\
\hline $\begin{array}{l}\text { Which is the most common fatal accident in children? } \\
<1 \text { (suffocation) } \\
1-4 \text { (transport) } \\
5-16 \text { (transport) }\end{array}$ & $\begin{array}{r}70(30 \cdot 6) \\
24(10 \cdot 5) \\
101(44 \cdot 1)\end{array}$ \\
\hline $\begin{array}{l}\text { What proportion of children attend an A \& E department each year as a } \\
\text { result of an accidental injury? ( } 1 \text { in } 6)\end{array}$ & $46(20 \cdot 1)$ \\
\hline $\begin{array}{l}\text { What percentage of the children attending an A \& E department following } \\
\text { an accidental injury are admitted to hospital? }(5-10 \%)\end{array}$ & $68(29 \cdot 7)$ \\
\hline $\begin{array}{l}\text { Which home accident causes most } A \& \text { E attendances? } \\
<1 \text { (fall) } \\
1-4 \text { (fall) } \\
5-16 \text { (fall) }\end{array}$ & $\begin{array}{l}23(10 \cdot 0) \\
28(12 \cdot 2) \\
42(18 \cdot 3)\end{array}$ \\
\hline $\begin{array}{l}\text { Where do most fatal accidents occur in children? } \\
<1 \text { (home) } \\
1-4 \text { (on the road) } \\
5-16 \text { (on the road }\end{array}$ & $\begin{array}{l}183(79 \cdot 9) \\
147(64 \cdot 2) \\
130(56 \cdot 8)\end{array}$ \\
\hline Do girls have more accidents that boys? (fewer) & $91(39 \cdot 7)$ \\
\hline $\begin{array}{l}\text { Which of the following are risk factors for childhood accidental injury? } \\
\text { Maternal age under } 20 \text { years (risk factor) } \\
\text { Single parenthood (risk factor) } \\
\text { Previous accidental injury (risk factor) } \\
\geqslant 4 \text { children in family (risk factor) } \\
\text { Socioeconomic deprivation (risk factor) } \\
\text { Family stress (risk factor) }\end{array}$ & $\begin{array}{l}166(72 \cdot 5) \\
151(65 \cdot 9) \\
149(65 \cdot 1) \\
154(67 \cdot 2) \\
188(82 \cdot 1) \\
203(88 \cdot 6)\end{array}$ \\
\hline
\end{tabular}

SIDS = sudden infant death syndrome; $A \& E=$ accident and emergency.

Table 3 Practice nurses' attitudes towards childhood injury prevention

\begin{tabular}{|c|c|c|c|}
\hline Attitudinal statement & $\begin{array}{l}\text { Agree or } \\
\text { strongly agree } \\
(\%)\end{array}$ & Neutral $(\%)$ & $\begin{array}{l}\text { Disagree or } \\
\text { strongly } \\
\text { disagree }(\%)\end{array}$ \\
\hline Most accidents are preventable $(n=228)$ & $203(88 \cdot 7)$ & $25(10.9)$ & 0 \\
\hline $\begin{array}{l}\text { I believe practice nurses can be effective in } \\
\text { preventing childhood accidents }(n=227)\end{array}$ & $106(46 \cdot 3)$ & $100(43 \cdot 7)$ & $21(9 \cdot 2)$ \\
\hline $\begin{array}{l}\text { Accident prevention is not a priority for me in } \\
\text { child health care }(n=228)\end{array}$ & $34(14 \cdot 8)$ & $62(27 \cdot 1)$ & $132(57 \cdot 7)$ \\
\hline $\begin{array}{l}\text { Other members of the PHCT have a greater } \\
\text { responsibility for accident prevention than } \\
\text { the practice nurse }(n=226)\end{array}$ & $95(41 \cdot 5)$ & $62(27 \cdot 1)$ & $69(30 \cdot 1)$ \\
\hline $\begin{array}{l}\text { Accident prevention should be discussed in } \\
\text { child health surveillance consultations } \\
(n=225)\end{array}$ & $183(80 \cdot 0)$ & $31(13 \cdot 5)$ & $11(4 \cdot 8)$ \\
\hline $\begin{array}{l}\text { Discussing accident prevention is important in } \\
\text { a consultation for an acute accidental injury } \\
(\mathrm{n}=228)\end{array}$ & $188(82 \cdot 1)$ & $24(10 \cdot 5)$ & $16(7 \cdot 0)$ \\
\hline $\begin{array}{l}\text { Practice nurses should give first aid advice in } \\
\text { consultations for acute accidental injury } \\
(n=226)\end{array}$ & $166(72 \cdot 5)$ & $45(19 \cdot 7)$ & $15(6 \cdot 5)$ \\
\hline $\begin{array}{l}\text { Practice nurses should routinely collect } \\
\text { information on childhood accidents }(n=228)\end{array}$ & $104(45 \cdot 5)$ & $96(41 \cdot 9)$ & $28(12 \cdot 2)$ \\
\hline $\begin{array}{l}\text { Practice nurses should be involved in lobbying } \\
\text { or campaigning on local safety issues } \\
(\mathrm{n}=228)\end{array}$ & $62(27 \cdot 1)$ & $119(52 \cdot 0)$ & $47(20 \cdot 5)$ \\
\hline $\begin{array}{l}\text { It is important for practices to display posters } \\
\text { and leaflets on accident prevention whenever } \\
\text { possible }(n=228)\end{array}$ & $205(89 \cdot 5)$ & $19(8 \cdot 3)$ & $4(1 \cdot 7)$ \\
\hline
\end{tabular}

PHCT = primary health care team. injuries are the most common fatal injury between 5 and 16 years $(56.8 \%$ responded correctly). More than two thirds identified the following risk factors for injury: young maternal age $(72.5 \%)$, large family size $(67 \cdot 2 \%)$, socioeconomic deprivation $(82.1 \%)$, and family stress $(88.6 \%)$. The maximum knowledge score obtainable on the questionnaire is 23; the actual scores obtained ranged from 0 to 18 (mean 10.7). Those with children, and those with experience of school nursing, had significantly higher knowledge scores (Mann-Whitney $U$ test $Z=-2.0, p=0.04 ; Z=-2.4, p=0.02$ respectively). No other associations were found between knowledge and personal characteristics of the nurses, including having a child who had had an injury.

ATTITUDES TOWARDS INJURY PREVENTION Highly significant correlations were obtained between each attitudinal statement and the total attitude score, with correlation coefficients ranging from 0.26 to 0.61 ( $p=0.001$ for all correlation coefficients). Internal consistency was assessed by Cronbach's alpha coefficient, which was 0.61 .

The attitudes of practice nurses towards injury prevention are shown in table 3 . Certain activities are regarded positively with the majority agreeing that most injuries are preventable $(88.7 \%)$, that prevention should be discussed in child health surveillance consultations $(80.0 \%)$, that they should give first aid advice $(72.5 \%)$, that injury prevention should be discussed in conultations for acute injury $(82 \cdot 1 \%)$, and that practices should display posters or leaflets on the subject $(89.5 \%)$. By comparison, relatively few believed they could actually be effective in preventing injuries $(46.3 \%)$ or that they should be involved in lobbying or campaigning on local safety issues $(27 \cdot 1 \%)$.

The maximum possible number of positive responses on the attitude score was 10 and scores ranged from 0 to 10 , with a mean of $6 \cdot 2$. There were no significant associations between personal characteristics and attitude score, nor was there a correlation between knowledge and attitude scores $(r=0.09, \mathrm{p}>0.05)$.

CURRENT PRACTICE IN INJURY PREVENTION The injury prevention activities are shown in table 4 . The activities most commonly undertaken are displaying posters and leaflets $(69.4 \%)$, discussing prevention of future injury in a consultation for acute injury $(51.1 \%)$, and giving advice on first aid in acute injury consultations $(45.0 \%)$. The activities least likely to be undertaken include working with a local child safety group (only $1.3 \%$ had done so in preceding two years), and lobbying or campaigning $(1.7 \%)$. Few $(6.6 \%)$ practice nurses had attended a course or lecture on child injury prevention in the preceding two years.

Twenty five per cent had not had contact with any other child care workers or health professionals about child safety in the preceding two years. Of those who had had such contacts, these were most often made within the primary health care team, with 
$67 \cdot 7 \%$ of practice nurses having contact with a health visitor, and $62.9 \%$ with a general practitioner concerning child safety in the preceding two years.

There were discrepencies between attitudes and practices for all activities. Of those agreeing in principle to the importance of various activities only $73 \%$ display leaflets and posters, $54 \%$ discuss injury prevention or first aid in consultations for acute injury, and only 5\% lobby on local safety issues.

\section{Discussion}

The social and occupational characteristics of the nurses responding to this survey are similar to those responding to previous surveys. ${ }^{346710}$ As has been previously demonstrated, a large proportion $(70 \%)$ entered practice nursing in the preceding five years, ${ }^{46710} \mathrm{few}$ are qualified health visitors, ${ }^{3710}$ and few have experience of school nursing. As regards injury prevention, although epidemiological knowledge is incomplete, more than half of the nurses correctly answered questions on most common cause of death above the age of 1 year, the site of most fatal injuries, and correctly identified the risk factors. Attitudes towards injury prevention activities were not uniformly positive, however, with less than one half believing they could be effective, despite almost $90 \%$ believing most injuries were preventable. There were also large discrepancies between the number of nurses holding positive attitudes towards injury prevention activities and the proportion undertaking these activities in practice.

The response rate in this study was high, and compares favourably with other surveys of practice nurses. ${ }^{36710}$ However, those responding are possibly those most interested in the subject and hence those most likely to have greater knowledge, more positive attitudes, and undertake more prevention activities. Caution should therefore be exercised in extrapolating these results to any wider population of nurses. Also, self reports of preventive activity by primary care physicians tend to overestimate activity when compared with medical record audits or patient surveys. ${ }^{20}$ It is likely that this phenomenon also applies to practice nurses. Consequently even the relatively low level of

Table 4 Practice nurses' current practices in injury prevention

\begin{tabular}{lccc}
\hline Current practice & $\begin{array}{c}\text { Always or } \\
\text { often }(\%)\end{array}$ & $\begin{array}{l}\text { Sometimes } \\
(\%)\end{array}$ & $\begin{array}{c}\text { Rarely or } \\
\text { never }(\%)\end{array}$ \\
\hline $\begin{array}{l}\text { How often, if ever, do you give advice about } \\
\text { safety equipment in child health surveillance } \\
\text { contacts? }(\mathrm{n}=205)\end{array}$ & $28(12 \cdot 2)$ & $84(36 \cdot 7)$ & $93(40 \cdot 6)$ \\
$\begin{array}{l}\text { How often, if ever, do you give advice about } \\
\text { first aid in consultations for acute accidental } \\
\text { injury? (n=227) }\end{array}$ & $103(45 \cdot 0)$ & $82(35 \cdot 8)$ & $32(14 \cdot 0)$ \\
$\begin{array}{l}\text { How often, if ever, do you discuss how future } \\
\text { accidents can be prevented when you see a } \\
\text { child following an acute accidental injury? } \\
\text { (n=214) }\end{array}$ & $117(51 \cdot 1)$ & $56(24 \cdot 5)$ & $41(17 \cdot 9)$ \\
$\begin{array}{l}\text { How often, if ever, when advising about safety } \\
\text { equipment, do you give details of local } \\
\text { stockists or local equipment loan schemes? } \\
\text { (n=200) }\end{array}$ & $13(5 \cdot 6)$ & $40(17 \cdot 5)$ & $147(64 \cdot 2)$ \\
$\begin{array}{l}\text { If you give advice about safety, how often, if } \\
\text { ever, do you also give parents a safety leaflet? } \\
\text { (n=200) }\end{array}$ & $16(11 \cdot 4)$ & $41(17 \cdot 9)$ & $143(62 \cdot 4)$ \\
\hline
\end{tabular}

activity reported in this study may be an overestimate.

It is nevertheless interesting and encouraging that, despite the lack of a clearly identified role for practice nurses in injury prevention, more than two thirds held positive attitudes towards some prevention activities, and that more than $50 \%$ were currently undertaking some such activities. The gap between attitudes and practice suggests there are barriers to undertaking injury prevention activities in routine practice. While more knowledge and skills in this area may be required, other constraints may also be operating. Previous work suggests that the reasons most commonly given by practice nurses for such limitations include lack of training, lack of time, the general practitioner's attitudes, and lack of confidence. ${ }^{7}$ Although none of these studies specifically concerned injury prevention, similar barriers are likely to apply in this area. Most practice nurses in this study do not believe that they can be effective in preventing children's injuries. The belief that a practitioner holds regarding their effectiveness in a particular situation is likely to determine activity in that situation. ${ }^{21-23}$ Consequently, unless practice nurses believe they can be effective they are unlikely to undertake injury prevention activities. Methods for increasing belief in self efficacy have been identified. These include providing opportunities for personal accomplishment, providing vicarious experience of accomplishment, verbal persuasion, and reducing anxiety associated with feelings of failure. ${ }^{22}$ Addressing these areas in training programmes specific to injury prevention may increase the nurses' sense of self efficacy and thus their involvement in injury prevention activities.

Other barriers to undertaking preventive activity in a primary care setting have also been identified. ${ }^{24-26}$ Activities aimed at improving the health of the population may not be seen by clinicians as relevant to their role with individual patients. Expressing the benefits of preventive activity in terms of individual patients or practice populations may, therefore, be more relevant to clinicians. ${ }^{24}$ Also, primary care clinicians traditionally have a reactive role, responding to patients complaints, rather than being proactive. Reminders to undertake a preventive activity may facilitate a more proactive role, ${ }^{2426}$ as may the contractual emphasis on health promotion in primary care. However, in primary care, acute problems take precedence over non-acute problems, and even if preventive services are prioritised, this will likely continue. ${ }^{24}$ Preventive services, by their nature, fail to provide positive feedback for the practitioner; one is rarely aware of an event that has been prevented. At the practice level it is unlikely that injury prevention programmes will be accompained by a noticeable reduction in injuries due to the relatively small numbers. Aggregating practice data may be a solution to this problem; alternatively process measures could be used to provide feedback. ${ }^{26}$ The implementation of formal systems for providing preventive services increases preventive 
activity. ${ }^{24}$ Although these evaluations do not include injury prevention programmes it is likely that the same principles will apply.

The finding that attitudes were most likely to be positive towards activities based on an educational model and that these are the activities most commonly undertaken, while activities such as lobbying or campaigning on safety issues are rarely undertaken, confirms previous work that practice nurses' use of 'radical' approaches to health promotion, such as the social change model, is limited. ${ }^{6}$ As the environmental approach to injury prevention has been demonstrated to be more effective than the educational approach, ${ }^{27-29}$ training covering other possible approaches, ${ }^{30}$ their relative effectiveness, and how to use them in everyday practice may be useful for these nurses.

The lack of an association between knowledge and attitude scores is interesting, as knowledge is thought to influence attitudes. ${ }^{21}$ The same questionnaire has been used on general practitioners and health visitors and for both groups a significant correlation between knowledge and attitude score was obtained (results presented elsewhere ${ }^{3132}$ ). However, both these professional groups had higher knowledge scores than the practice nurses. It is therefore possible that the relationship between knowledge and attitudes is not a simple linear one, and that there is a threshold above which knowledge and attitude scores correlate. However, the numbers of practice nurses with high knowledge scores in this study were too small to investigate this hypothesis further.

\section{Conclusion}

The role of the practice nurse should not be viewed in isolation but rather as part of all the injury prevention activities of the primary health care team. ${ }^{14}$ Members of the team may have differing areas of expertise, differing interests, and differing opportunities to undertake such activities. These factors may change over time and with changes in the composition of the team. Therefore, it is important that members are aware of each other's roles, that they adapt to changing circumstances, and that each team defines the roles of its members based on the needs of the practice population, as well as being based on the expertise, opportunities, and interests of the team members. ${ }^{24}$ This study suggests that at least some practice nurses are interested in injury prevention and are willing to undertake activities in this area. Whether they should do so remains to be answered, and until more information is available on their effectiveness in this area, the question will remain open for debate.

We would like to thank the practice nurses in Nottinghamshire for completing the questionnaire. We are also grateful to the
Child Accident Prevention Trust for permission to adapt and use their 'picture of childhood accidents' questionnaire. This study was funded by the Department of Health.

1 Steering group. Report on the training needs of practice nurses. London: Royal College of Nursing, 1984.

2 Robinson H, Robinson A. A survey of practice nurses in Northern Ireland: identifying education and training needs. Health Education fournal 1993; 52: 208-12.

3 Cant S, Killoran A. Team tactics: a study of nurse collaboration in general practice. Health Education fournal 1993; 52: 203-7.

4 Peter A. Practice nursing in Glasgow after the new general practitioner contract. Br $\mathcal{F}$ Gen Pract 1993; 43: 97-100.

5 Hibble A. Practice nurse workload before and after the introduction of the 1990 contract for general practiintroduction of the 1990 contract for
tioners. Br $\mathcal{F}$ Gen Pract 1995; 45: 35-7.

6 Bradford M, Winn S. A survey of practice nurses' views of health promotion. Health Education fournal 1993; 52: 91-5.

7 Greenfield S, Stilwell B, Drury M. Practice nurses: social and occupational characteristics. $\mathcal{F} R$ Coll Gen Pract 1987; 37: $341-5$.

8 Mourin $K$. The role of the practice nurse. $f R$ Coll Gen Pract 1980; 30: 75-7.

9 Powell RA. The practice nurse - a review. $f R$ Coll Gen Pract 1984; 34: 100-1.

10 Ross FM, Bower P, Sibbald BS. Practice nurses: characteristics, workload and training needs. $B r f$ Gen Pract 1994; 44: 15-8.

11 Department of Health. The health of the nation: key area handbook - accidents. London: Department of Health, 1993.

12 Quick A. Unequal risks: accidents and social policy. London: Socialist Health Association, 1991.

13 Roberts $\mathrm{H}$. Accident prevention: a community approach Health Visitor 1991; 64: 219-20.

14 Kendrick $D$. Role of the primary health care team in preventing accidents to children. Br f Gen Pract 1994; 44: 372-5.

15 Steiner DL, Norman GR. Health measurement scales: a practical guide to their development and use. Oxford: Oxford University Press, 1991: 46-9.

16 Child Accident Prevention Trust. The health visitors' education and training resource. London: Child Accident Prevention Trust, 1991.

17 Office of Population Censuses and Surveys. Mortality statistics: injury and poisoning 1991. (Series DH4 No 17.) London: HMSO, 1993.

18 Department of Trade and Industry. Home accident surveillance system: report on 1993 accident data and safety research. London: Department of Trade and Industry, 1995

19 Department of Trade and Industry. Home and leisure accident research: eleventh annual report. Home accident surveillance system: report on 1987 data. London: Department of Trade and Industry, 1989.

20 Lewis CE. Disease prevention and health promotion practices of primary care physicians in the United States. $A m \mathcal{F}$ Prev Med 1988; 4: 9-16.

21 Fishbein M, Ajzen I. Belief, attitude, intention and behaviour: an introduction to theory and research. Massachusetts: Addison-Wesley Publishing Company, 1975.

2 Bandura A. Self-efficacy: toward a unifying theory of behavioral change. Psychol Rev 1977; 84: 191-215.
and

23 Bandura A. The self system in reciprocal determinism. Am Psychol 1978; 33: 345-58.

24 Kottke TE, Brekke ML, Solberg LI. Making 'time' for preventive services. Mayo Clin Proc 1993; 68: P785-91.

25 Pommerenke FA, Dietrich A. Improving and maintaining preventive services. Part 1: applying the patient model. $\mathcal{F}$ Fam Pract 1992; 34: 86-91.

26 Pommerenke FA, Dietrich A. Improving and maintaining preventive services. Part 2: Practical principles for primary care. $\mathcal{f}$ Fam Pract 1992; 34: 92-7.

27 Towner E, Dowswell T, Jarvis S. Reducing childhood accidents. London: Health Education Authority, 1993.

28 Pless B. The scientific basis of childhood injury prevention. $A$ review of the medical literature. London: Child Accident review of the medical liter

29 Haddon $W$. Energy damage and the 10 countermeasure strategies. F Trauma 1973; 13: 321-31.

30 Child Accident Prevention Trust. Basic principles of child accident prevention. London: Child Accident Prevention Trust, 1989.

31 Kendrick D, Marsh P, Williams EI. General practitioners, child accident prevention and the 'health of the nation' Health Education Research (in press).

32 Marsh P, Kendrick D, Williams EI. Health visitors' knowledge, attitudes and practices in childhood accident prevention. $f$ Public Health Med (in press). 